\title{
Effects of Calcium and Phosphorus Supplementation on Metabolic Bone Disorders in Premature Infants
}

\author{
Debabrata Roy ${ }^{1 *}$, M. A. Mannan ${ }^{2}$, Farhana Afroj ${ }^{3}$, Nahida Islam ${ }^{4}$
}

${ }^{1}$ Junior Consultant, Department of Pediatrics, Upazila Health Complex, Kaliakair, Gazipur, Bangladesh

${ }^{2}$ Professor, Department of Neonatology, Bangabandhu Sheikh Mujib Medical University (BSMMU), Dhaka, Bangladesh

${ }^{3}$ Assistant Professor, Department of Pediatrics, Kumudini Medical College Hospital, Tangail, Bangladesh

${ }^{4}$ Lecturer, Department of Community Medicine, Government Homeopathy Medical College Hospital, Dhaka, Bangladesh

DOI: $10.36347 /$ sjams.2020.v08i12.037

| Received: 22.09.2020 | Accepted: 08.10.2020 | Published: 29.12.2020

*Corresponding author: Dr. Debabrata Roy

Abstract

Original Research Article

Introduction: Every year, 15 million babies are born prematurely around the world of which more than 1 million die as a result of prematurity. Premature infants are considered to be at high risk for developing osteopenia due to their reduced bone mineral content. Mothers milk containing 25-35 mg/dl of calcium and 10-15 mg/dl of phosphorus simply does not contain enough minerals to support skeletal growth of growing premature infants. Supplement of calcium and phosphorus along with breast milk can reduce the rate of osteopenia and improve the growth of premature infants. Objective of the study: To determine the efficacy of calcium and phosphorus supplementation for prevention of metabolic bone disease and improvement of growth in preterm infants. Methodology: A randomized clinical trial study was conducted at the Department of Neonatology, BSMMU, from $16^{\text {th }}$ August 2016 to $27^{\text {th }}$ August 2017 . It involved monitoring 50 premature neonates over a period of six weeks. The babies who were fed with breast milk were randomly divided into two equal groups. One group received supplement of calcium and phosphorus along with breast milk while other group did not receive any supplement. Serum calcium, phosphorus and alkaline phosphatase levels as well as growth parameters (including weight, length, and head circumference) were measured at enrollment and at 6 weeks post birth. At the end of 6 weeks, wrist X-ray was done for evaluation of osteopenia. Data was analyzed using SPSS version 20. Results: Radiological and biochemical evidence of metabolic bone disease were found in $6(28 \%)$ supplemented group and $7(35 \%)$ non supplemented group $(p=0.45)$. S. calcium, S. inorganic phosphate and S. alkaline phosphatase level were comparable at enrollment between two groups. At 6 weeks S. calcium, S. inorganic phosphate level were more $(9.5 \pm 0.4 \mathrm{mg} / \mathrm{dl} \mathrm{Vs} 9.4 \pm 0.5$, and $357 \pm 253 \mathrm{U} / \mathrm{L} \mathrm{Vs} 4.4 \pm 1.2$ respectively) and $\mathrm{S}$. alkaline phosphatase level were less $(4.8 \pm 1.1 \mathrm{mg} / \mathrm{dl} \mathrm{Vs} 4.4 \pm 1.2 \mathrm{mg} / \mathrm{dl})$ in supplemented group than non-supplement group, but no significant change was observed between two groups. The mean of weight, length and head circumference were also comparable at enrollment between two groups. At 6 weeks' growth velocity considering weight, length and head circumference were more at supplemented group but no significant change were observed between two groups. Conclusion: Infants of supplemented group showed better growth velocity and lower incidence of metabolic bone disorders than non-supplemented group. But this difference between supplemented group and nonsupplemented group were not statistically significant. However, his study does not provide any evidence to suggest the effectiveness of supplementary calcium and phosphorus in osteopenia.

Keywords: Calcium, Phosphorus, Metabolic Bone Disorders, Premature Infants.

Copyright $\odot 2020$ The Author(s): This is an open-access article distributed under the terms of the Creative Commons Attribution 4.0 International License (CC BY-NC 4.0) which permits unrestricted use, distribution, and reproduction in any medium for non-commercial use provided the original author and source are credited.

\section{INTRODUCTION}

Every year, 15 million babies are born prematurely around the world of which more than 1 million die as a result of prematurity [1]. However, the continuous developments in intensive care of premature newborns have led to a progressive decline in mortality. The achievement in the survival through an intensive care is not always ensured a favorable long-term outcome of premature newborn. Prematurity is the greatest risk factor for metabolic bone disease because most calcium and phosphorus deposition occurs during the third trimester [2]. In preterm newborn with gestational age below 32 weeks, the mineral content of bone is $25 \%-70 \%$ less than term neonates [3]. Metabolic bone disease is characterized by a reduction in bone mineral content (osteopenia), with or without rachitic changes. It presents between 6 and 12 weeks of age but may remain asymptomatic for weeks until overt rickets or fractures. Symptoms may include poor weight gain, faltering growth, and respiratory difficulties or failure to wean off ventilator support due to excessive chest wall compliance. Fractures may manifest 
as pain on handling. A combination of phosphorus less than $4.6 \mathrm{mg} / \mathrm{dL} \quad(<1.49 \mathrm{mmol} / \mathrm{L})$ and $\mathrm{S}$. Alkaline Phosphatase greater than $900 \mathrm{IU} / \mathrm{L}$ yielded a sensitivity of $100 \%$ and a specificity of $70 \%$ for low bone mineral density. Experts recommend radiography of the wrist and/or knee because these regions are of high metabolic activity. There is also a grading system for assessing radiological severity. Mothers milk containing 25-35 mg/dl of calcium and $10-15 \mathrm{mg} / \mathrm{dl}$ of phosphorus simply does not contain enough minerals to support skeletal growth of growing premature infants. Bangladesh is among the top 10 countries with the highest numbers of preterm birth. The number has been increasing along with the global rise of incidence ${ }^{1}$. In Bangladesh, Prevalence of osteopenia is high $(28 \%)$ in premature infants. So, supplement of calcium and phosphorus along with breast milk in premature infants may prevent metabolic bone disease and improve the growth of premature infants.

\section{OBJECTIVES}

To observe the efficacy of calcium and phosphorus supplementation for prevention of metabolic bone disease and improvement of growth in preterm infants.

\section{Methodology \& MATERIALS}

This study was conducted in the department of neonatology, Bangabandhu Sheikh Mujib Medical University from $16^{\text {th }}$ August 2016 to $23^{\text {rd }}$ July, 2017. During the study period, 187 preterm infants $\leq 34$ weeks' gestation were admitted in the Neonatal Intensive Care Unit. Of them 62 neonates meet inclusion criteria. This was a randomized clinical trial where 25 preterm babies were enrolled in supplement and non-supplement group (One group received supplement of calcium and phosphorus along with breast milk while other group did not receive any supplement). So, total 50 neonates were enrolled after taking informed written consent from parents of the selected neonates. Ethical clearance obtained from Institutional Review Board (IRB) of BSMMU to undertake the current study. They were divided into two groups (Supplemented and non-supplemented group) by lottery method. At 6 weeks, 21 patients in supplement and 20 patients in non-supplement group were available for analysis. But one in supplement group and two in nonsupplement group lost follow up. Two patients in supplement group and one in non-supplement group died. One in supplement group and two in non-supplement group developed feeding intolerance. After collection, data were entered into a personal computer and were edited, analyzed, plotted and were in graphs and tables. Data were analyzed by chi square test, and student's t test using the statistical package for social sciences (SPSS) version 20.

\section{Inclusion Criteria}

- All the admitted preterm baby <34 weeks who received oral feeding at least $5 \mathrm{ml} /$ feed 2 hourly total 12 feed in a day within seven days of postnatal age.

\section{Exclusion Criteria}

- Infant receiving medications that interfere calcium and phosphate metabolism (aminophylline, anticonvulsants, diuretics, corticosteroids).

- After starting of supplementation if feed is hold for consecutive 3 days or more.

- Born by mother with known osteomalacia, diabetes, parathyroid gland disease and renal disorders.

- Parental refusal for including in study.

\section{RESULT}

Demographic characteristics of studied infants are presented in Table 1. Mean gestational age, birth weight, length and Occipito frontal circumference of supplemented group were $33.7 \pm 2.2$ weeks, $1353 \pm 206$ grams, $39.7 \pm 2.8 \mathrm{~cm}$ and $28.6 \pm 1.5 \mathrm{~cm}$ respectively. Mean gestational age, birth weight, length and OFC of nonsupplemented group were $33.1 \pm 2.7$ weeks, $1405 \pm 263$ grams, $39.2 \pm 2.9 \mathrm{~cm}$ and $28.0 \pm 1.7 \mathrm{~cm}$ respectively. Gender distribution reflects slight male predominance in nonsupplemented group. But there was no statistical significant difference between two groups. Table 2 shows S. Calcium, S. alkaline phosphatase and S. inorganic phosphate value of infants of two groups at enrollment. There was no statistical significant difference between two groups. Of the 41 infants, 13 (32\%) developed evidence of osteopenia considering biochemical and radiological abnormality (Table-3). Out of 13 patients 12 had radiological evidence of osteopenia and 1 patient had osteopenia by biochemical evidence only. 6 patients had both biochemical and radiological evidence of osteopenia. Among the radiological evidence $11(92 \%)$ had grade 1 and 1 patients $(8 \%)$ had grade 2 (Table-3). At 6weeks of age S. Calcium and S. inorganic phosphate and S. Alkaline Phosphatase value of supplemented group were $9.5 \pm 0.4$ $\mathrm{mg} / \mathrm{dl}, 4.8 \pm 1.1 \mathrm{mg} / \mathrm{dl}$ and $357 \pm 253 \mathrm{U} / \mathrm{L}$ respectively. At 6 weeks of age $\mathrm{S}$. Calcium and $\mathrm{S}$. inorganic phosphate and S. Alkaline Phosphatase value of non-supplemented group were $9.4 \pm 0.5 \mathrm{mg} / \mathrm{dl}, 4.4 \pm 1.2 \mathrm{mg} / \mathrm{dl}$ and $538 \pm 271 \mathrm{U} / \mathrm{L}$ respectively. There was no statistical significant difference between two groups (Table-4). Infants of supplemented group showed better growth velocity considering weight, length and Occipito frontal circumference but there was no significant difference between two groups (Table-5).

Table-1: Comparison of demographic data between two groups $(\mathbf{n}=50)$

\begin{tabular}{|l|l|l|l|}
\hline \multicolumn{1}{|c|}{ Parameter } & Supplemented group & Non Supplemented group & p Value \\
\hline \multicolumn{1}{|l|}{ Sex } & 11 & 11 & 0.55 \\
\hline Fale & 10 & 9 & 0.28 \\
\hline Gemale & $33.7 \pm 2.2$ & $33.1 \pm 2.7$ & 0.37 \\
\hline Body Weight of the neonate (Gram) Mean \pm SD & $1353.81 \pm 206$ & $1405 \pm 263$ & 0.48 \\
\hline Body length of the neonate (cm) Mean \pm SD & $39.7 \pm 2.8$ & $39.2 \pm 2.9$ & 0.72 \\
\hline OFC of the neonate (cm) Mean \pm SD & $28.6 \pm 1.5$ & $28 \pm 1.7$ & \\
\hline
\end{tabular}


Table 2: Comparison of serum calcium, alkaline phosphatase and inorganic phosphate level in supplemented and NonSupplemented group at enrollment $(\mathbf{n}=50)$

\begin{tabular}{|l|l|l|l|}
\hline Parameter & Supplemented group & Non Supplemented group & P value \\
\hline S. Calcium $(\mathrm{mg} / \mathrm{dl})(\mathrm{mean} \pm \mathrm{SD})$ & $8.8 \pm 0.6$ & $8.8 \pm 0.7$ & 0.2 \\
\hline S. ALP $(\mathrm{U} / \mathrm{l})(\mathrm{mean} \pm \mathrm{SD})$ & $211 \pm 55$ & $226 \pm 64$ & 0.4 \\
\hline S. inorganic phosphate $(\mathrm{mg} / \mathrm{dl})($ mean \pm SD) & $4.8 \pm 1.3$ & $4.8 \pm 1.8$ & 0.09 \\
\hline
\end{tabular}

Table-3: Comparison between radiological and biochemical evidence of osteopenia in preterm neonates in supplemented and Non-Supplemented group at 6 th week of age $(\mathbf{n}=50)$

\begin{tabular}{|l|l|l|l|}
\hline \multirow{2}{*}{ Parameter } & \multicolumn{2}{|c|}{ Osteopenia } & \multirow{2}{*}{ P value } \\
\cline { 2 - 3 } & Present & Absent & \\
\hline Supplemented group N(\%) & $6(28 \%)$ & $15(72 \%)$ & 0.45 \\
\hline Non Supplemented group N(\%) & $7(35 \%)$ & $13(65 \%)$ & \\
\hline
\end{tabular}

Table-4: Comparison of serum calcium, alkaline phosphatase and inorganic phosphate level in supplemented and NonSupplemented group at 6 weeks where $(n=50)$

\begin{tabular}{|l|l|l|l|}
\hline Parameter & Supplemented group & Non Supplemented group & P value \\
\hline S. Calcium $(\mathrm{mg} / \mathrm{dl})($ mean $\pm \mathrm{SD})$ & $9.5 \pm 0.4$ & $9.4 \pm 0.5$ & 0.6 \\
\hline S. ALP $(\mathrm{U} / \mathrm{l})($ mean $\pm \mathrm{SD})$ & $357.5 \pm 253$ & $538.2 \pm 271$ & 0.39 \\
\hline S. inorganic phosphate $(\mathrm{mg} / \mathrm{dl})($ mean $\pm \mathrm{SD})$ & $4.8 \pm 1.1$ & $4.4 \pm 1.2$ & 0.5 \\
\hline
\end{tabular}

Table-5: Comparison of values of weight, length and head circumference in premature neonates receiving supplements and in the Non Supplemented group group at $6^{\text {th }}$ weeks $(n=50)$

\begin{tabular}{|l|l|l|l|}
\hline Parameter & Supplemented group & Non Supplemented group & P value \\
\hline Body Weight of the neonate $(\mathrm{Gram})$ Mean \pm SD & $2326.7 \pm 602$ & $2301 \pm 721$ & 0.3 \\
\hline Body length of the neonate (cm) Mean \pm SD & $46.2 \pm 3.6$ & $44.6 \pm 5.5$ & 0.14 \\
\hline Occipito frontal circumference Mean \pm SD & $33.7 \pm 2.2$ & $33.1 \pm 2.6$ & 0.28 \\
\hline
\end{tabular}

\section{DISCUSSION}

This study tried to determine effects of calcium and phosphorus supplementation on radiological and biochemical characteristics of osteopenia and growth in premature infants. Total 13 patients out of 41 patients had evidence of osteopenia of prematurity (Rate $32 \%$ ). Out of
13 patients 12 had radiological evidence of osteopenia and 1 patient had osteopenia by biochemical evidence only. 6 patients had both biochemical and radiological evidence of osteopenia. Among the radiological evidence 11(92\%) had grade 1 and $1(8 \%)$ patient had grade 2 .

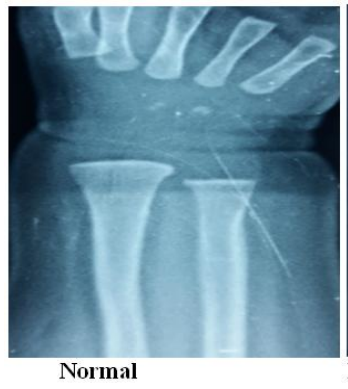

Patients of supplemented group showed better growth velocity and lower incidence of MBD though there was no statistical significant change. This study showed that adding supplement of calcium and phosphorus in premature infants did not have a significant effect on the rate of osteopenia. Some studies have shown similar results [4-6]. Growth and bone mineral deficiencies were compared in 38 preterm infants fed fortified mother's milk and 21 preterm infants fed a preterm formula until they reached $1800 \mathrm{~g}$; all had a birth weight below $1600 \mathrm{~g}$. Weight gain was similar in each group with a mean (SD) increase of $19.6(3.5) \mathrm{g} / \mathrm{kg} /$ day in the fortified group and $19.9(4.1) \mathrm{g} / \mathrm{kg} /$ day in the preterm formula group. There were also no significant differences in linear growth, head circumference, skin fold thickness or mid-arm circumference. Serum phosphate, alkaline phosphatase and plasma urea concentrations were similar and there was no

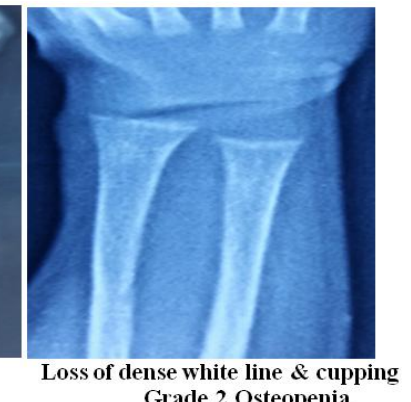

Grade 2 Osteopenia clinical evidence of osteopenia [7]. Zohre Torabi [8] in their study compared the impact of calcium and phosphorus on radiological and biochemical characteristics of osteopenia in premature infants. Radiological changes, characteristic of osteopenia, were found in $8(40 \%)$ cases and $13(65 \%)$ controls $(\mathrm{p}<0.113)$. The mean of weight, length and head circumference increased significantly from second to sixth week during follow-up $(\mathrm{p}<0.0001)$. Phosphorus and alkaline phosphatase activity decreased significantly from second to sixth week of follow-up $(\mathrm{p}<0.02, \quad \mathrm{p}<0.01$ respectively). However, repeated measurement analyses did not show significant effect of intervention in biochemical and growth parameters in the trial group. Total 40 premature neonates were included. These results are consistent with current study. However, there were several studies that demonstrated the beneficial effects of supplementary feeding on the reduction of 
osteopenia and improvement of bone mineral contents [913]. Lapillonne [14], in their study showed that compared to control subjects, infants fed the experimental formula had $25 \%$ and $40 \%$ higher intakes of calcium and phosphorus, respectively. Serum calcium, phosphorus, osteocalcin, and alkaline phosphatase concentrations and urinary collagen type I cross-linked N-telopetide concentrations were not significantly different between the groups at any time point. The bone mineral content of infants fed the experimental formula was $23 \%(\mathrm{P}=0.039)$ and $35 \%(\mathrm{P}=0.002)$ higher at hospital discharge and expected term respectively [14]. These results might be due to the prescription of different doses of supplements or minerals or the age of neonates at the time of study or other environmental factors. One study showed positive effect of adding supplementary nutrients with different mineral contents in 3 groups of neonates in comparison to neonates who were only breast-fed. It found that different concentrations of minerals produced no significant changes in the intervention groups [15]. This trial did not show any significant effect on calcium, phosphorus and alkaline phosphatase levels as the two groups. In this study, the weight and linear and head growth of the intervention infants was $s$ higher at the sixth week of the study. However, the trial had no significant effect on growth parameters. Still, there are several studies that do not support the effectiveness of supplementary feeding on growth parameters [5, 12]. In the present study all the three expired patient was diagnosed as a case of late onset neonatal sepsis. One was Acinetobacter sp. And another one was Klebsiella sp. positive. Third one was diagnosing as a case of late onset sepsis by clinically and positive septic screening. Total three patients developed feeding intolerance which managed by nil per os for 5 days and then restart feeding gradually.

\section{Limitations of the study}

Our study wasn't a blinded study so patient bias was present along with observer bias in subjective recording and the small sample size, single center study, blinding was not done, short follow up period.

\section{CONCLUSION AND RECOMMENDATIONS}

Infants of supplemented group showed better growth velocity and lower incidence of metabolic bone disorders than non-supplemented group. But this difference between supplemented group and nonsupplemented group were not statistically significant. However, his study does not provide any evidence to suggest the effectiveness of supplementary calcium and phosphorus in osteopenia of prematurity and growth of infants. Further studies of longer duration, large sample size and with different doses of supplement are recommended.

\section{REFERENCES}

1. Blencowe H, Cousens S, Oestergaard MZ, Chou D, Moller AB, Narwal R, Adler A, Garcia CV, Rohde S, Say L, Lawn JE. National, regional, and worldwide estimates of preterm birth rates in the year 2010 with time trends since 1990 for selected countries: a systematic analysis and implications. The lancet. 2012 Jun 9;379(9832):2162-72.

2. Abrams D, Crisp RJ, Marques S, Fagg E, Bedford L, Provias D. Threat inoculation: experienced and imagined intergenerational contact prevents stereotype threat effects on older people's math performance. Psychology and aging. 2008 Dec;23(4):934-939.

3. Klinger G, Levy I, Sirota L, Boyko V, Reichman B, Lerner-Geva L, Israel Neonatal Network. Epidemiology and risk factors for early onset sepsis among very-lowbirthweight infants. American journal of obstetrics and gynecology. 2009 Jul 1;201(1):38-e1.

4. Bryan SM, Hindmarsh PC. Normal and abnormal fetal growth. Horm Res. 2006:65(13):19-27.

5. Carrascosa A, Yeste D, Copil A, Almar J, Salcedo S, Gussinye M. Patrones antropométricos de los recién nacidos pretérminos ya términos (24-42 semanas de edad gestacional) en el Hospital materno-Infantil Vall d'Hebron (Barcelona). An Pediatr (Barc). 2004;60:40616.

6. Cooper C, Javaid MK, Taylor P, Walker-Bone K, Dennison E, Arden N. The fetal orgins of osteoporotic fracture. Clalcif Tissue Int. 2002:70:391-4.

7. Warner JT, Cowan FJ, Dunstan FD, Evans WD, Webb DK, Gregory JW. Measured and predicted bone mineral content in healthy boys and girls aged 6-18 years: adjustment for body size and puberty. Acta Paediatrica. 1998 Mar;87(3):244-9.

8. Torabi Z, Moemeni N, Ahmadiafshar A, Mazloomzadeh $S$. The effect of calcium and phosphorus supplementation on metabolic bone disorders in premature infants. J Pak Med Assoc. 2014 Jun;64(6):635-9.

9. Alvino G, Cozzi V, Radaelli T, Ortega H, Herrera E, Cetin I. Maternal and fetal fatty acid profile in normal and intrauterine growth restriction pregnancies with and without preeclampsia. Pediatric research. 2008 Dec;64(6):615-20.

10. Barker DJP, Osmnd C, Forsen TJ, Kajantie E, Eriksson JG. Trajectories of growth among children who have coronary events adults. NEJM. 2005:353(17):1802-9.

11. Carrascosa A, Yeste D, Copil A, Almar J, Salcedo S, Gussinyé M. Patrones antropométricos de los recién nacidos pretérmino ya término (24-42 semanas de edad gestacional) en el Hospital Materno-Infantil Vall d'Hebron (Barcelona)(1997-2002). InAnales de Pediatría 2004 Jan 1 (Vol. 60, No. 5, pp. 406-416). Elsevier Doyma.

12. Drake AJ, Walker BR. The intergenerational effects of fetal programming: non-genomic mechanisms for the inheritance of low birth weight and cardiovascular risk. J Endocrinol. 2004:180:1-16.

13. Dunger DB, Petry CJ, Ong KK. Genetic variations and normal fetal growth. Hormone Research in Paediatrics. 2006;65(Suppl. 3):34-40.

14. Lapillonne, A., Salle, B.L., Glorieux, F.H. and Claris, O., 2004. Bone mineralization and growth are enhanced in preterm infants fed an isocaloric, nutrient-enriched preterm formula through term. The American journal of clinical nutrition, 80(6), pp.1595-1603.

15. Ehrenberg HM, Dierker L, Milluzzi C, Mercer BM. Low maternal weight, failure to thrive in pregnancy, and adverse pregnancy outcomes. American journal of obstetrics and gynecology. 2003 Dec 1;189(6):1726-30. 